Hyland, K. \& Jiang, K. (2020). "This work is antithetical to the spirit of research": An anatomy of harsh peer reviews. Journal of English for Academic Purposes. 46

\title{
"This work is antithetical to the spirit of research": An anatomy of harsh peer reviews
}

\section{Introduction}

One of the constants of the rapidly changing landscape of academic publishing is peer review, and perhaps the deep aversion authors seem to have for it (e.g. Davidoff, 2004; Jefferson et al, 2007; Smith, 2006). While digital publishing, Open Access, multiple authorship, publishing oligopolies and metrics-driven competition have replaced earlier practices, peer review remains a cornerstone of quality control. Prestigious journals stake their reputations on the quality of the papers they publish and therefore on the standards of their peer review, leading to rejection rates in the top humanities journals as high as 90\% (APA, 2017). For many academics, however, this filtering of academic research is a fraught experience, especially as careers now depend on whether (and where) research is published. The experience for writers can be especially traumatic where reviews are overly critical or wilfully obtuse (e.g. Wilcox, 2019). In this paper we explore extracts of reviews authors have received on their submissions which they regard as particularly harsh and suggest how authors may deal with such comments.

To do this we examine a corpus of 850 excerpts posted by authors on the publicly accessible shitmyreviewerssay ${ }^{1}$ website. Our study seeks to explore these critical comments and identify some of the features which authors find so discouraging or scathing that they chose to share them with the academic community at large. In doing so we hope to not only describe the ways reviewers have expressed these highly critical and hurtful comments but also to contribute to a wider conversation concerning the feedback academics receive on their work and encourage more mentoring and formative practices. Specifically, we seek to answer the following questions:

(1) What is the main evaluative focus of these reviews?

(2) How do reviewers express the stance they take in critical reviews?

(3) What evaluative items distinguish these reviews from other academic genres?

\footnotetext{
${ }^{1}$ http://shitmyreviewerssay.tumblr.com
} 


\section{Peer review and its discontents}

Peer review contributes to the creation and archiving of knowledge in several ways. For readers, it acts as a filter. With more than a million papers published each year, academics can only keep abreast of significant work if trusted reviewers pre-read the literature. For authors, reviewers' reports provide an indication of how another researcher understands their work and its contribution, with reviewer feedback often bringing 'revise and resubmit' papers to publication. Most centrally, however, peer review helps screen submissions for publication, providing the expertise and time that editors themselves might lack.

Unreviewed research posted on personal websites is regarded with scepticism by the academic community. In their study of 4000 researchers, for example, Mulligan et al. (2013) found that most respondents saw peer review as 'the most effective mechanism for ensuring the reliability, integrity, and consistency of the scholarly literature' ( $p$. 149). The academic community's support for the practice is also evidenced in two large scale surveys of over 6000 academics in each. These show that reviewers typically spend five hours on each review and do this largely because they want to contribute to the academic community and improve new papers (Publishing Research Consortium, 2016; Taylor and Francis, 2015). Others, particularly early career researchers, may feel motivated by being trusted to comment on a peer's work by an editor, to be a part of professional debates and to gain experience which may improve their own writing.

In fact, peer review underpins how academia sees itself and, indeed, embodies two of Merton's (1973) four norms defining scientific practice. Peer review contributes to Universalism, or an adherence to objectivity rather than personal self-interest, and to Organised scepticism, so that no theory is accepted merely on the authority of the proponent. It is often seen as the cornerstone of academic credibility and fundamental to the development and integration of new research (Hyland, 2015). More generally, of course, it reaches deep into the lives of individual researchers so that appearing in peer-reviewed publications has become the benchmark for ranking scholars in a very high stakes game. Publication recognises a paper's worth and an academic's credibility. 
Despite its role in screening the torrent of research output, several major criticisms have been levelled at it, particularly as peer review is exclusionary and often influenced as much by available journal space as by the excellence of the paper. Over the last 20 years, for example, Nature has published only $8 \%$ or so of the 10,000 submissions it receives each year (Nature, 2018). The massive surge in submissions in the last decade, combined with the ever-narrower niche coverage of journals, has put enormous pressure on peer review and forced editors to cast their nets wider in search of willing readers. At the same time, reviewing itself has become an increasingly marginalised part of an academic's role. Because reviewing is pro bono work done without reward or credit, it is vulnerable to increasing workloads and the greater expectations placed on academics by their employers for more teaching, more administration and more research.

This is a situation which has resulted in what Sciullo and Duncan (2019) recently described as

... a preponderance of incompetent reviewers, a lack of constructive criticism and the maintenance of orthodoxy, relative ease in identifying blinded authors, editorial passivity, and long waits to receive reviews.

As a result, a recent study of editors and reviewers in software engineering, for example, found that two thirds of reviews were considered misleading or merely adequate (Prechelt et al. 2017). Clearly the system is under some considerable strain.

\section{Comment and criticism in peer reviews}

Reviews are now far less of an "occluded genre" (Swales, 1996) than they were 20 years ago, and we have a better idea of what we are likely to find in them. Typically, for example, they focus on the content and argument of submissions (e.g. Coniam, 2012; Mungra \& Webber, 2010; Mur Dueñas, 2012) and while negative comments on style or language are common (Mur Dueñas, 2012; Hewings, 2004) the quality of the language rarely seems to be a decisive factor in rejection (Belcher, 2007; Coniam, 2012). Judgements recommending revisions are substantially longer than those which advise rejection or acceptance (Hewings, 2004; Coniam, 2011) and editors seem to value reviews that are longer and include more comments on goals, analyses and claims (Falkenberg \& Soranno, 2018). 
Criticism, of course, is a key feature of reviews, and may comprise up to half of all comments (Fortanet, 2008). These comments can sometimes be blunt (Kourilova, 1996), perhaps because of reviewer anonymity, a hurried report, personal style or even or a lack of pragmatic competence. EAL reviewers make up an increasing proportion of reviewers (Hyland, 2015) and seem far more direct than native English speakers (Paltridge, 2017). Belcher (2007), however, discovered considerable politeness in reviews and Hyland's (2015a) study of 150 peer reviews from leading applied linguistics journals, found directness to be rare with both criticisms and suggestions largely mitigated. Reviewers syntactically subordinated criticism to praise by preceding a negative comment with a positive one and softened the negativity of the overall evaluation with hedges and by asking questions rather than firmly asserting censure. Certainly, analyses of reviews show considerable use of attitude markers and self-mention to emphasise the reviewer's certainty and authority (Paltridge, 2017), but generally reviewers seek to create a positive, sympathetic relationship with writers.

The difficulties of gaining access to authentic examples of peer reviews means that much of what has been said about them is anecdotal. Journal editors in applied linguistics, however, are in a better position to collect actual review samples and have taken the opportunity to publish analyses of them (e.g. Paltridge, 2017; Hyland, 2015; Tardy, 2019; Belcher, 2007). It is possible that those who study language for a living might be more sensitive to its pragmatic impact on readers and write more gentle reviews. But directness, of course, has the advantage of not leaving authors feeling unsure what they are being asked to do in revising a paper. Mitigation and politeness can tone down the interpersonal impact of critical comments but make it more challenging for newcomers to interpret.

Criticism, of course, can actively contribute to improving a text and there is evidence to suggest that the more revisions a paper undergoes, the greater its citation impact (Rigby et al 2018). But not all reviewers are paragons of mentoring, working with authors to bring manuscripts to publication. The very act of evaluating another's work is a thinly disguised instructional relationship of authority; an inherently unequal interaction because the power to criticise is non-reciprocal and lies exclusively with the reviewer. This is perhaps made more threatening by the fact that 
reviewers are "mysterious and intimidating figures" (Tardy, 2019), masked by anonymity, with the power to influence our professional lives. Clearly reviewers' reports can be demoralizing and while anonymity might help prevent personal bias, it can make reviewers less accountable. This can be extremely demotivating, as Kwan has observed:

Many first-time writers are confused, discouraged or even shocked by the negative reviews they receive, and the substantial revisions requested...Some never attempt to revise and resubmit their work that reviewers see as having potential for publication.

(Kwan, 2010, 213)

Studies of authors' perceptions suggest that many authors put their difficulties down to the fact they are writing in a foreign language (e.g. Hanauer \& Englander, 2011; Ferguson et al, 2011; Hwang, 2005). A key issue for many novices appears to be the lack of an appropriate conceptual framework which allows them to speak with authority (e.g. Badenhurst et al, 2015). Cameron et al (2009) and Shirey (2013), for example, talk of the strong emotions of self-doubt, anxiety and erosion of confidence experienced by novice academic writers, many seriously troubled by the fear of rejection (Oermann \& Hays, 2011). Academic writing for publication is undoubtedly what Aitchison et al (2012) call 'emotional work' which creates strong feelings of both joy and pain. Few find writing easy or enjoyable and receiving critical comments can exacerbate negative feelings, as Mertkan points out:

Those new to peer review are largely unaware of the (sometimes) harsh criticism that is part of the cut and thrust or negotiating the process, one which more established scholars recognise as par for the course. (Mertkan, 2016: 148)

The studies summarised here, however, have addressed only two areas: the language of peer reviews and the difficulties authors experience in the publication process. We know little, however, about how authors find discouraging or hurtful about the criticisms they contain. To address this gap, we take a rather novel approach. Instead of asking scholars for their views, which tells us little about the actual comments they receive, we have chosen to look at the comments themselves and, in particular, those identified by authors as particularly savage or wounding. These comments are 
selected by the recipients from reviews they have received and posted on a website designed for the purpose of sharing harsh and negative reviews.

We assume, then, that the comments posted are seen as caustic and unhelpful by authors, and by focusing on these we are able to identify some of the features which make them so. We should point out here that we do not believe these comments are typical of the tens of thousands of reviews written every day, which are generally helpful and supportive. However, by drawing attention to them we hope to provide guidance for reviewers when judging manuscripts (Wallwork, 2016) and advice for authors who might receive them.

\section{Data source and method}

We used the free data mining tool Web Scraper to extract all the extracts from peer reviews posted by authors on the shitmyreviewerssay website hosted on tumblr. As stated on the website, these extracts are

"a celebration of the harsh, the weird, the passive aggressive, the active aggressive and the downright mean comments practicing scientists receive on a regular basis".

The site exists, at least in part, to allow authors to vent their frustrations and expose poor reviewing. It asks authors to post short quotes which are real sentences from reviews the poster has received and which are self-explanatory and not dependent on background knowledge of a disciplinary field. We were able to obtain 850 posted texts which had been uploaded to the site between 2014 and mid-2019, totalling 16,148 words. We then stored the output from this extraction process in plain text format to allow searching, concordancing and analysis.

We are interested in three main areas of analysis. First, the evaluative focus of the comments, what the reviewers addressed; second, the stance taken by the reviewer in the extract; and third, the word forms which are particularly common in a given text: those which are key to it.

Ideally, we would have preferred to compare these harsh reviews with others that are less severe, but a sufficiently large corpus for this purpose is virtually impossible to 
collect. Not only are peer review comments generally inaccessible to public gaze ${ }^{2}$, but the ethical obstacles involved in both collecting such reviews and gaining the permissions of reviewers to quote from them presents an almost insurmountable challenge (cf Paltridge, 2017). Because of this, we decided to statistically compare the word frequencies in our shitmyreviewersay corpus against the 16 million words of the academic genres of the British National Corpus, a collection of published academic written texts. Using the text analysis software AntConc (Anthony, 2019) we discovered the Keywords which characterise our corpus from academic writing more generally, identifying items which are most prominent and not just frequent.

The evaluative foci were explored through a manual search of the corpus and assigning topics to categories proposed by Hewings (2004) and Coniam (2012). Both authors worked on this and compared results to ensure inter-rater reliability, achieving a score of 95\%. Finally, we used Hyland's (2005b) framework to search for items expressing evidentiality, affect and presence. Again, the small size of the corpus permitted a manual search following a concordancing of the texts. Working independently, both authors coded the markers with reference to this framework and achieved $97 \%$ agreement.

In the following sections we discuss the findings of these analyses.

\section{Evaluative focus: what the reviewers are critical about}

To explore the content focus of the criticism in the corpus we first looked at the previous literature to see how researchers had categorised the comments in peer reviews. Gosden (2003) found that reviewers mainly addressed technical detail (27\%) and the discussion (34\%) while Hewings (2004) reported that reviewers for the English for Specific Purposes mainly evaluated the paper's overall quality and contribution (22\%) as well as the quality of claims (19\%) and the analysis (18\%). Coniam (2012) studied his own reviews for the language teaching journal System over 8 years, a total of 122 texts. He found that he had rejected $93 \%$ of papers with negative comments most often addressing the acceptability of claims (in $80 \%$ of the reviews), the methodology (in

\footnotetext{
${ }^{2}$ As we write this in February 2020, the journal Nature has announced it will publish peer reviews along with the paper as a trial https://www.nature.com/articles/d41586-020-00309-9
} 
$65 \%)$, the sufficiency of data $(60 \%)$ and the clarity of research questions (58\%). Content and methodology also dominated critical comments in both Mungra and Webber's (2010) study of Italian scholars submitting to medical journals and in Mur Dueñas's (2012) sample of Spanish researchers' submissions in Finance.

These categorisations are not identical but cover similar ground and provided the basis for our own organisation of the content we found in the comments. We independently scoured the corpus and gradually refined our groupings, adding a category relating to the competence of the authors, which did not figure in the other studies. In this way we arrived at the following broad areas which include all comments:

i. Author competence: Concerning the abilities of the writers to conduct and present research suitable for publication.

(1) The authors are amateurs.

(2) Frankly, she knows nothing about invasion biology or the Great Lakes.

ii. Overall verdict: An overall comment on the submission as a whole, its originality contribution to knowledge and the acceptability of the claims, and whether it meets the standards for journal publication:

(3) This manuscript is obviously not suitable for publication in a high impact factor journal.

(4) It cannot be reviewed and should be rejected outright.

iii. Quality of the arguments: Whether the submission is persuasive, coherent and lucid for disciplinary readers.

(5) The paper is ill-informed and poorly argued.

(6) Most part of 'methodology' is useless, most paragraphs are irrelevant to the main topics.

iv. Structure and language: The overall structure of the submission, the length, the adherence to academic conventions and use of grammatical and appropriate language.

(7) The writing and data presentation are so bad that I had to leave work and go home early and spend time to wonder what life is about. 
(8) The English language ranks this manuscript among the top 5 worst manuscripts I have ever reviewed

v. Research design: The clarity of the research questions, the nature of the data, how the research was conducted and appropriacy of the analysis

(9) The first problem is that the method - whatever it is and however it works - is insufficiently evaluated.

(10) There is no need to test these hypotheses. They have been tested a long time ago. It is in all textbooks.

Because the extracts are concise, they almost always address just one of these areas, but we distinguished remarks into separate categories in the few cases where a single comment had two foci. In this example, for instance, the reviewer comments on both the design of the study and the authors themselves:

(11) There are two possibilities. 1) This paper is part of an experiment to try and determine how badly a research paper can be but still be accepted, or 2) The authors are actual fools and it would be in the editor's best interest to ban them from submitting to the journal in the future.

Based on these categories, we counted the frequencies of occurrence and these are presented in Table 1 in terms of the percentages of all comments.

Table 1 The proportions of evaluative focus in the corpus (\%)

\begin{tabular}{cccccc}
\hline Author & Overall & Argument & Language & Design & Total \\
\hline 24.5 & 29.9 & 12.8 & 11.3 & 21.5 & 100 \\
\hline
\end{tabular}

In Coniam's (2012) study of peer reviews, the quality of the argument receives the most attention, accounting for up to $30 \%$, which shows that peer reviewers are principally concerned with the acceptability and soundness of academic arguments. However, what authors feel most stung by, perhaps because this criticism condemns their entire project and carries the greatest weight with editors, is the overall verdict on the manuscript. These comments comprise $30 \%$ of the total and contribute to the 
final decision on the paper as editors are looking for a global assessment of the paper to make a decision on how they should proceed with the submission.

(12) Unfortunately, I cannot recommend this paper for publication because its contents violate the laws of physics.

(13) This paper is so bad I cannot even reject it!

(14) I do not want to see the paper again.

These unequivocal statements on the value of the paper as a whole are damning: expressing the clear opinion of the reviewers and leaving the author in no doubt of the outcome of the submission.

Perhaps equally wounding for authors is personal criticism of their competence, and such comments comprised a surprising $24.5 \%$ of the items in the corpus. The literature reporting studies of peer review comments tends to suggest that reviewers are largely preoccupied with methods, style, argument structures and an editorial recommendation (e.g. Paltridge, 2017). However, for some reviewers, perhaps frustrated or irritated by being asked to read a particularly poor paper, the gloves are off regarding mentioning the authors themselves.

(15) It is clear that the author has read way too much and understood way too little.

(16) The authors conclusions not only contradict their own data but also the laws of thermodynamics.

(17) The author does not exhibit adequate acquaintance with the subject under discussion, the scholarship on it, the structure of logical argument, or the writing of English.

Clearly these reviewers are unimpressed by what they are reading and have decided to make their feelings clear by addressing the authors directly and negatively. For the authors themselves, this warrants inclusion on the website.

The third most frequent category in this corpus of harsh reviews, with $21.5 \%$ of the total, is commentary on study design. The research design is the framework for the entire study, situating the problem, identifying the methods, and influencing how the data should be collected and analysed. It governs the reviewers' assessments of 
quality of scientific inquiry in terms of validity, objectivity and accuracy (Kumar, 2011). Comments such as these seem particularly wounding for authors:

(18) Usually climate studies do not show a good method for the proposed research. This is one of them.

(19) Right now, there is zero rationale for the study and zero reason to read the study.

(20) It looks to be more of a chance for the authors to promote a product using a poorly constructed, non-replicable pilot study

Fierce criticism or dismissive comments on their research design thus undermines the authors' sense of scientific credentials and ability to conduct serious research. It is not surprising that they choose to post these comments most frequently on the website. Finally, we will just mention the attention given to the quality of the argument in these texts. It is often difficult to categorically identify where reviewers are referring to the argument rather than the design or making an overall verdict on whether the paper is publishable, and so we focused on those comments which refer to specific aspects of the presentation, as here:

(21) Table 4 seems unnecessary given figure 8 . Indeed, figure 8 also seems unnecessary.

(22) I just don't get the point of this

(23) The authors report results from pages 16-26. This section reflects what I would brutally call 'death by figures'

In these examples, and others like them, reviewers are criticising the soundness and veracity of the presentation, holding up weaknesses to criticise specific aspects of the argument. Once again, authors find these statements sharp enough to warrant sharing with their peers online.

\section{Critical stance: how reviewers position themselves in comments}

The second research question we addressed concerns the writer's use of explicit markers of epistemic and attitudinal stance in these reviews. While the opinions of the reviewers on the submitted texts are unambiguously expressed through the keywords and focus of the criticism, the ways writers step into their texts to express a stance is a key component of evaluation. Hyland (2005b, p. 176) describes stance as: 
features which refer to the ways writers present themselves and convey their judgements, opinions, and commitments. It is the ways that writers intrude to stamp their personal authority onto their arguments or step back and disguise their involvement.

Following Hyland (2005b, p. 178), we see stance as a writer-oriented feature of interaction which allows writers to comment on the possible accuracy or credibility of statements, how far they want to commit themselves to these comments, and the attitude they want to convey to a proposition or the reader.

This framework encompasses three main components: evidentiality, affect and presence.

- Evidentiality - the writer's stated commitment to the reliability of statements and their potential impact on the reader, expressed through hedges and boosters

- Affect - a range of attitudes towards what is said expressed through attitude markers

- Presence - the extent to which a writer chooses to intrude into a text through the use of first person pronouns and possessive determiners.

Using this framework, we identified 1,192 stance expressions in the corpus, averaging 1.4 cases in every extract. This is an enormously high frequency compared with other genres (e.g. Hyland, 2005b) and underlines the extremely evaluative nature of these texts where authors feel that reviewers have overstepped the mark in criticising their work. These examples illustrate these stance categories, where reviewers use hedges and boosters to modify the certainty of an assertion (24), the expression of attitude (25) and the use of authorial presence (26):

(24) The entire paper reads a bit like someone who has searched around the social scientific research literature without much authentic understanding of social science.

(25) This is such a promising topic, but I was very disappointed in this paper combining a substantial amount of author talent.

(26) I am, frankly, underwhelmed by the revisions.

Table 2 shows the distribution of these stance markers in the corpus. 
Table 2 Distribution of stance markers in the corpus

\begin{tabular}{lcc}
\hline & frequency & \% \\
\hline Boosters & 404 & 33.9 \\
\hline Self-mention & 339 & 28.4 \\
\hline Attitude markers & 277 & 23.2 \\
\hline Hedges & 172 & 14.4 \\
\hline Total & $\mathbf{1 1 9 2}$ & $\mathbf{1 0 0 . 0}$ \\
\hline
\end{tabular}

As we can see, boosters are the most predominant stance marker in these texts, conveying the reviewer's conviction and certainty in their judgement and ensuring there is no doubt about their opinion. This finding is in direct contrast to much research writing where hedges dominate the frequencies, offering writers a prudent option in a context which rewards appropriate caution in stating claims and interpretations to acknowledge colleagues' potentially dissenting views and to head off their objections (Hyland, 2005a). In the genre of peer review, Paltridge (2017: 125 ) found that boosters comprised just $4 \%$ of stance markers in texts recommending 'accept' and $1.5 \%$ in those in 'reject' reviews. Paltridge has little to say about the use of boosters, but presumably the reviewers were concerned to avoid bald-on-record, confrontational statements and to offer a more supportive stance.

In our corpus of negative reviews and particularly forthright comments, in contrast, the writer wishes to be perfectly clear rather than conciliatory, sending a recommendation to the editor and a message to the writer:

(27) The Discussion section of the paper is neither informative nor enlightening and is certainly theoretically questionable.

(28) This paper must be rejected, because the work it describes is clearly impossible.

(29) The writer of the manuscript is utterly ridiculous and appears to believe they will solve poverty through radio astronomy. 
Clearly there is the manifestation of a power imbalance here (Hyland \& Giuliana, 2009), and the reviewers leave authors in no doubt of their authority through the reinforcement of their judgements using boosters.

An authoritative tone is conveyed in a different way by the use of first person. Attributing a claim to themselves gives writers a clear voice and allows them to take responsibility for an unambiguous assertion of a belief or judgement. For readers, it conveys the strong impression that this is the writer's robust and unshakable evaluation. Self-mention comprises over $28 \%$ of stance markers and indicates the confidence expressed in what is said, as in these examples:

(30) I was really looking forward to reading this manuscript, however this enthusiasm soon waned.

(31) Not only does this strike me as the worst kind of postmodern legerdemain, but if true I believe the statement would transform ethics into a hopelessly muddled enterprise.

Self-mention was also a statistically significant feature of Hyland's (2015) peer reviews from applied linguistics journals. Reviewers displayed a high level of certainly in what they had to say, especially in both the major revisions and reject reviews in Paltridge's (2017) English for Specific Purposes corpus. Presumably reviewers did not want to appear as being uncertain or ambiguous about the judgements they were making. Signalling critical comment as a personal opinion allows reviewers to make adjust the interactional context and foreground an authoritative persona. But while in Hyland and Paltridge's reviews it was often used with hedges or combined with a positive comment in good news - bad news pairs, in these harsh comments, it is used to present a statement without dressing or varnish; it is disparagement from the heart:

(32) I do not want to see the paper again.

(33) I felt like I was reading a horror movie...

(34) I cannot possibly imagine what could have led the authors to believe that their paper was remotely interesting enough to submit for publication. 
These are evaluations conveyed with authority and spoken without fear of contradiction. The abstracts are too short to inform us whether the reviewers have provided supporting argument or back-up evidence for their statements, the criticisms are made confidently. Clearly these reviewers feel able to assert their claim to speak as authorities. The fact these were posted online shows that the submitting authors did not find these assertions welcome.

Another stance feature used to convey the strength of a writer's opinion is the use of attitude markers. These indicate the writer's affective response to propositions, conveying annoyance, agreement, importance, frustration, and so on, rather than commitment to their truth (Hyland, 2005a). This is a stance option which is relatively infrequent in research writing (Hyland \& Jiang, 2016) and tends to be implicitly invoked rather than openly inscribed (Martin \& White, 2005). However, in Paltridge's 'accept' and 'minor revisions' reviews (Paltridge, 2017:124-7), they comprised half of all markers, complimenting the author on a good submission by drawing on shared positive values (Hyland, 2005b), as in "The manuscript is well documented, well structured and relevant".

In our corpus attitude markers made up about half of all stance features and contributed to highly critical evaluations, with forms being almost entirely negative. The emphatic expression of affect in this way is conveyed largely by attitude verbs (e.g. disagree, reject), sentence adverbs (unfortunately, absurdly), and adjectives (inappropriate, illogical) and in these texts conveys strong disapproval. These examples give some flavour of this:

(35) I have rarely read a more blown-up and annoying paper

(36) An exercise in feature manipulation, of the brainless kind

(37) However, bad language, weird sentences, half true statements and even nonsense statements continue throughout the draft.

Such personal and scathing comments clearly have the potential to deflate the confidence of authors.

These expressions of stance, however, are not evenly distributed among the different evaluative foci that we discussed in the previous section, revealing something of the complexity of these criticisms. Table 3 shows this distribution. 
Table 3 Distribution of stance markers across evaluative foci (\%)

\begin{tabular}{lrrrrrr}
\hline & Author & Overall & Argument & Language & Design & Total \\
\hline Boosters & 7.2 & 29.1 & 19.6 & 28.7 & 15.4 & 100 \\
\hline Self-mention & 7.7 & 33.1 & 11.5 & 20.6 & 27.1 & 100 \\
\hline Attitude & 19.1 & 20.8 & 15.9 & 23.8 & 20.4 & 100 \\
\hline Hedges & 28.3 & 27.9 & 17.4 & 6.4 & 20.0 & 100 \\
\hline
\end{tabular}

As we noted in Table 1, overall judgement carries the highest proportion of evaluative focus in the corpus and here we find the greatest concentration of stance markers. In particular, there is a very strong author presence in these comments, it is the focus of the text where reviewers reveal their presence most explicitly (33\%). Clearly, these reviewers intend to project a certainty in their overall verdict, delivering a judgement in no uncertain terms with self-mention:

(38) Unfortunately, I cannot recommend this paper for publication because its contents violate the laws of physics.

(39) In my view the manuscript provides a relatively superficial summary of the area which lacks any attempt at interpretation or novelty.

(40) This is a disaster. I could continue, but you see my point.

Here the comment carries the unambiguous finality of authority. It is the considered judgement.

Apart from the overall assessment, the category where reviewers were most likely to boost their assessments was when commenting on the language and presentation of submissions (28.7\%). Language, and more broadly the conventions of disciplinary writing, is a key issue in academic publishing, particularly to L2 authors and novice writers (e.g. Habibie \& Hyland, 2019) and it figures in most reviews (see section 2 above). For some reviewers, the quality of the writing was sufficiently poor to warrant the use of additional emphasis:

(41) The manuscript is poorly written ... and a review by a native English speaker is clearly needed. 
(42) The biggest problem with this manuscript, which has nearly sucked the will to live out of me, is definitely the terrible writing style.

The combination of negative attitude markers and boosters leaves the submitting author under no illusions that the English is adequate. A clear attitudinal stance is also taken towards what are seen as inappropriate or inadequate use of discursive conventions:

(43) The paper is presented as a rather undigestible and tortuous collection of disparate results

(44) First, the paper is for a large part incomprehensible

The design of the study, which attracts a fifth of all comments in these posted extracts, is also heavily stance laden, and it is some of the choices of attitude marker which carry the greatest impact:

(45) The study is poorly conceived and inadequately conducted and the conclusions do not necessarily follow from the results (46) The data you have are weak, based on very small samples, not clear that they were analyzed properly, and are based on measurements taken in the wrong medium for the organisms.

Design is the heart of a research project and the study stands or falls on how it has been conceived and conducted. Such strongly marked criticism of this fundamental aspect is likely to hurt. It shows, however, how clearly reviewers intended to convey their views.

Finally, and in contrast to the comments on language and arguments, reviewers took some care to soften their criticisms of the authors themselves with the use of hedges, which contained $28 \%$ of all these markers. Hedges have been found to be important in published academic book reviews to tone down criticisms and reflect a positive relationship with the reader and the author (Hyland, 2005b). Similarly, in these harsh reviews, hedges indicate that reviewers do not wish to disrespect authors entirely and that some mitigation of the interpersonal damage caused by these critical comments is required, at least when it comes to addressing the authors themselves:

(47) Maybe the authors should cite a reference intended for nonmathematicians instead of Akaike (1974), which I guess that they have read and understood. 
(48) Perhaps my greatest criticism of the paper is the tendency of the authors to make an argument and then to almost immediately contradict themselves repeatedly.

We have been at pains to point to the directness and insensitivity of these reviews, but while mitigation is not a salient feature, there is here at least an acknowledgement that the submitting author deserves some consideration.

\section{Keywords in the reviews: what are they about?}

The final question concerns what lexical features distinguish these harsh reviews from other academic genres. The basic concept here is keyness: the idea that a word form or cluster of words that are statistically more frequent in a corpus than expected are key to it. They distinguish the corpus and represent "what it boils down to ...once we have steamed off the verbiage, the adornment, the blah blah blah" (Scott \& Tribble, 2006, p.56). Keywords can also "specify the salient features which are functionally related to the genre" (Grabowski, 2015, p. 24). Our comparison of the critical corpus with the BNC academic genres found 155 keywords. Table 4 shows the 10 with the highest keyness value.

Table 4 The top 10 keywords in the review corpus

\begin{tabular}{|c|c|c|c|}
\hline keyness & frequency & effect & keywords \\
\hline$+\quad 1333.7$ & 221 & 0.023 & authors \\
\hline+692.03 & 360 & 0.014 & this \\
\hline$+\quad 664.69$ & 204 & 0.010 & not \\
\hline+546.21 & 500 & 0.009 & is \\
\hline+464.22 & 211 & 0.009 & paper \\
\hline+401.65 & 71 & 0.006 & manuscript \\
\hline$+\quad 298.42$ & 29 & 0.004 & reviewer \\
\hline$+\quad 234.09$ & 85 & 0.006 & you \\
\hline$+\quad 197.93$ & 41 & 0.005 & $\mathrm{am}$ \\
\hline$+\quad 175.34$ & 23 & 0.003 & journal \\
\hline
\end{tabular}


It is not surprising that paper and manuscript are on the list, as reviewers often refer to the text they are reading. Unlike many other academic genres, reviews are most centrally concerned with explicitly "evaluating the research, the texts and the contributions of fellow academics" (Hyland \& Giuliana, 2009, p. 1), rather than primarily promoting new research. In other words, the paper or manuscript is the object of study rather than some aspect of the physical or social world. Criticism is often directed at flaws which are seen to lie with the academic work as a whole, rather than a specific aspect of it:

(49) This paper is absolutely ridiculous.

(50) The manuscript embarrassingly fails in addressing the declared aims.

(51) Publication of this paper will not advance our knowledge in any shape of form, it will just result in other researchers pointing out how bad this study actually is.

(52) I have read this MS twice, which ... would appear to be more times than it has been read by the authors.

While the text is the target of peer reviews, it is interesting to see that authors has the highest keyness, indicating that authors, by posting the comments on the site, may feel personal comments on their academic competence particularly keenly:

(53) The authors are actual fools and it would be in the editor's best interest to ban them from submitting to the journal in the future.

(54) While it is true that the authors are under no "legal" obligation to cite these results, as they are unpublished, they are probably morally obliged to consider what they tell us in comparison with their own results.

(55) I am personally offended that the authors believed that this study had a reasonable chance of being accepted to a serious scientific journal.

While we cannot be sure that the appearance of this item in the negative comments is unusual or not, it seems that harsh criticisms in close proximity to authorial reference has the potential to undermine the author's confidence in his or her scholarly abilities and may be seen as particularly severe, a finding which is supported by the fact that 
positive reviews tend to contain far fewer explicit mentions of the author (Paltridge, 2017).

The fact that it ranks highest on the keyword list is obviously of some concern when considering these review extracts. We may, however, attribute its use to a belief that feedback given directly to authors can be more effective in bringing about change than a less personal reference to the text itself (Hyland \& Hyland, 2019). Despite its baldon-record directness, participant-oriented evaluation can direct authors to reflect on what they have done and guide them to much needed revisions:

(56) The authors do not control for the height of their subjects in their experiment. What they call prejudice against women may be argued to be prejudice against shorter people.

(57) The authors have entered a controversial area, ... they need to make sure their research will stand up under the inevitable scrutiny.

The use of the second person you is even more imposing as it addresses the author directly as a responsible agent, accountable for the issue under scrutiny. You draws the author into the text to offer suggestions that are intended to be read as directions (Paltridge, 2015). O'keeffe, Clancy, and Adolphs (2011), for example, argue that this direct speech act underlines a suggestion and can be particularly effective suggestion when it is made by someone with more power than the addressee. Once again, the fact that it is a keyword in these posted extracts suggests that this usage may be unwelcome by manuscript authors.

(58) I would suggest that you do some homework and redirect this work to an actual new and novel and mechanistic work and test it against real world data.

(59) You should consider consulting a competent statistical adviser.

Another participant, aside from the submitting author, on the keyword list is reviewer. Interestingly however, this is not usually a self-reference to the writer of the current review, but an intertextual reference to the perspectives of other reviewers. Occasionally, they also seem to be overarching comments by the editor of the journal.

(60) I totally agree with the reviewer 1 that this paper is still difficult to read even after revision. 
(61) Please respond to the reviewer 2's comments, who suggested rejection of the paper.

While there is often disagreement among reviewers regarding whether needed changes are minor or major, one of the roles an editor plays is to highlight the next steps and clarify what is important for authors. Comments such as these, however, leave authors in a difficult position to make a rebuttal.

This is another keyword worthy of attention. It appears frequently as a determiner or pronoun in the BNC (Leech, Rayson, \& Wilson, 2001), but is far more prominent in the review corpus. Of the 360 cases of this, $35 \%$ are sentence initial, referring anaphorically to something previously mentioned. What follows this therefore provides a critical commentary on the referent.

(62) This result would be great if it were true

(63) This sentence is so hard to digest and gave me reflux.

About $60 \%$ of all cases of this are unattended with an accompanying noun and predicated by copular verbs. As Jiang and Wang (2018) have shown, a single demonstrative pronoun this gives writers the rhetorical potential to achieve effective reference to an immediate antecedent or a generalised proposition, and the imposing effect is enhanced by the copular verb predication, which signals a shift from an observation to evaluation that unfolds in the predicative discourse. As seen in Table 4, this rhetorical device is widely used in the harshest review comments.

(64) This is a sin of omission!

(65) This is a rather pedestrian treatment of a popular and well-reported topic.

(66) This is a disaster. I could continue, but you see my point.

The criticality of these harsh reviews means that it is not surprising to find not on the keyword list. We notice, however, that in half of all cases, reviewers reserve this negative for a verdict on the submission, either commenting on its research value or its suitability for the journal:

(67) This paper should not be published.

(68) The opinion expressed in the MS is highly biased and patriotically motivated, and is not suitable for publication in this journal. 
(69) That's not how science is done.

We also find is in the keyword top ten in these harsh reviews, so even though it is common in the BNC reference corpus (Leech et al., 2001) it is statistically more frequent in our corpus. Is has a definiteness absent from a lot of academic writing, however, where it is often replaced by a hedging modal such as might or may. A sweep of concordances shows that is commonly collocates with this paper, and overwhelmingly appears as an attributive form of relational process (Halliday \& Matthiessen, 2014). That is, is assigns an evaluative attribute, rather than an identifying one, to the feature discussed by the reviewer. Thus it is a strategy to express "the enactment of appraisal" (Halliday \& Matthiessen, 2014, p. 273).

(70) this paper is extremely lengthy and tedious with respect to its importance and relevance.

(71) this paper is oblique to the entire current literature and fails to relate such investigations as it reports to the current literature....

It is interesting to discover, moreover, that is rarely collocates with this study in these extracts from harsh reviews, suggesting that judgements on the research product, rather than the process, may be seen by authors as more wounding.

Another reason for the prominence of $i s$ in the reviews is the high frequency of the introductory it pattern compared with the reference corpus. In this pattern, is follows the dummy subject pronoun $i t$, linking an adjective clause in the form of a that-clause, to-infinitive clause or wh-clause. As

(72) It is difficult to see the merits of this proposal, and it is doubtful whether the author has the necessary command of primary and secondary sources to contribute anything to this area of research.

(73) I think the N-mixture modeling should be abandoned: it is clear that the authors do not understand this class of models.

This structure is an effective means of making an evaluative comment on the unfolding proposition while remaining in the background (e.g. Dong \& Jiang, 2019). In these texts, reviewers use the device to either attack the quality of manuscripts (see 72) or criticise authors' research capability (73) and to do so without making themselves explicitly visible in the texts. This helps to disguise the personal and subjective nature 
of the harsh evaluation and suggest that this is an everyman opinion, i.e. an assertion that the other members of the community might share. Clearly, the fact that sufficient numbers of receivers have posted extracts with this structure shows that they still regard the comments as unacceptable.

\section{Final thoughts and implications for EAP}

Peer review is a contentious yet, thus far, apparently indispensable aspect of publishing: contributing to the creation and archiving of accredited knowledge and the construction of scholarly careers. In this paper we have explored reviews which their receivers have found so harsh, offensive or otherwise unacceptable that they have chosen to share them publicly on a site created for this purpose. Using corpus techniques, we have identified the content foci, stance features and keywords of these reviews to show how the texts differ from our expectations of collegial behaviour and to highlight both what authors find wounding and, by implication, what reviewers might seek to avoid.

Clearly, while reviewer comments are primarily a quality control mechanism in publishing, they are also have considerable potential in mentoring junior scholars in both conducting collegial interactions and improving their papers. The journal Nature, for example, advises its 'many tens of thousands of reviewers', thus:

The primary purpose of the review is to provide the editors with the information needed to reach a decision. The review should also instruct the authors on how they can strengthen their paper to the point where it may be acceptable. As far as possible, a negative review should explain to the authors the weaknesses of their manuscript...

(Nature website: http://www.nature.com/authors/policies/peer_review.html) The reviews analysed here, however, suggest that the practice does not always meet these goals and that the experience of authors can be closer to an ordeal by fire than progress through the zone of proximal development.

We should, once again, state clearly that we do not wish to contribute to the reviewerbashing widely seen on the internet and heard in university corridors. We do not believe the texts we have analysed in this paper are in any way typical of the thousands of peer reviews written every day in every discipline. Indeed, it is the very 
novelty and bizarre untypicality of these extracts which have encouraged authors to post them. There are well over 70,000 peer reviewed academic journals in the world (Ulrich, 2019) and the ScholarOne manuscript processing system receives 1.9 million submissions annually (Clarivate, 2019). Reviewers are in high demand so that just one publisher, Elsevier, made use of 700,000 reviewers in 2015 alone (Reller, 2016).

Because of this, reviewer shortages are now critical which increases the likelihood that the number of acerbic reviews will increase. The work has become a marginalised part of an academic's role, so that even willing reviewers are often forced to do a hurried job. Reviewing is done without financial reward or institutional credit, and so time for it suffers as universities demand more teaching, more administration, more outreach and more publishing. These competing pressures mean that academics are often forced to squeeze the task into ever shrinking time windows or decline requests and so force editors to turn to untried individuals. Either way, the quality of reviews can suffer and encourage bad tempered or caustic comments.

An additional problem fuelling the possibility of harsh reviews is that academics very rarely receive training in peer review, either from publishers or in $\mathrm{PhD}$ programmes. Some journals have initiated such reviewer training, but it is clear from the examples discussed in this paper that it should not be confined to improving analytical and diagnostic skills. Establishing criteria for 'good reviews' clearly involves a mentoring dimension which will have the effect of mitigating harsh reviews and encouraging reviewers to be constructive in their feedback. Given their expertise with language and familiarity with the pragmatic impact of rhetorical decisions in writing, it is not unreasonable to suggest that EAP teachers are well placed to initiate and lead such workshops.

The role of EAP teachers in the publishing process might also profitably be extended to courses which advise junior scholars how to respond to reviewer comments. Given the industrial scale of the publishing enterprise, there will inevitably be reviews which are blunt and rude among them and authors will have to deal with these during their careers. PLOS (Public Library of Science), the large non-profit open-access science, technology and medicine publisher, suggests 10 'rules' for responding to reviewers (Noble, 2017). In addition to urging authors not to take things personally or get 
offended, they suggest re-reading comments over several days until achieving a more objective 'mental clarity' on how to address them politely. It is certainly important to have an open mind and identify reviewers' concerns to frame a response, but it is equally essential to avoid emotion and sweeping opinion statements of disagreement. Little can be gained by biting back. There are no thin-skinned academics; or at least not among those who publish regularly. The intervention of EAP teachers can be decisive in assisting novice scholars with their initial steps into the publishing arena and exploration of how we might best accomplish this offers exciting opportunities for the future of our field.

\section{References}

Aitchison, C., Catterall, J., Ross, P., \& Burgin, S. (2012). 'Tough love and tears': learning doctoral writing in the sciences, Higher Education Research \& Development, 31(4), 435-447.

Anthony, L. (2018). AntConc (Version 3.4.3 w) [Computer Software]. Tokyo, Japan: Waseda University. Retrieved from http://www.antlab.sci.waseda.ac.jp/

APA (2017) Summary report of journal operations. https://www.apa.org/pubs/journals/features/2016-statistics.pdf

Biber, D., S Johansson, G Leech, S Conrad, \& E Finegan. (1999). Longman grammar of spoken and written English. Harlow: Longman.

Badenhorst, C., Moloney, C., Rosales, J., Dyer, J., \& Ru, L. (2015) Beyond deficit: graduate student research-writing pedagogies, Teaching in Higher Education, 20(1). 1-11.

Belcher, D. (2007). Seeking acceptance in an English-only research world. Journal of Second Language Writing, 16, 1-22.

Cameron, J., Nairn, K., \& Higgins, J. (2009). Demystifying academic writing: reflections on emotions, know-how and academic identity. Journal of Geography in Higher Education, 33(2), 269-284.

Clarivate Analytics (2019). ScholarONe. https://clarivate.com/products/scholarone/

Coniam, D. (2012). Exploring reviewer reactions to manuscripts submitted to academic journals. System, 40(4), 544-553.

Davidoff, F. (2004). Improving peer reviews: Who's responsible? BMJ, 328, 658659. 
Dong, J., \& Jiang, F. (2019). Construing Evaluation Through Patterns: Registerspecific Variations of the Introductory it Pattern. Australian Journal of Linguistics, 39(1), 32-56.

Falkenberg, L. J., \& Soranno, P. A. (2018). Reviewing Reviews: An Evaluation of Peer Reviews of Journal Article Submissions. Limnology and Oceanography Bulletin, 27(1), 1-5. https://doi.org/10.1002/lob.10217

Ferguson, G., Pérez-Llantada, C., Plo, R. (2011) 'English as an international language of scientific publication: a study of attitudes'. World Englishes 30,1, 41-59.

Fortanet, I. (2008), Evaluative language in peer review referee reports. English for Academic purposes, 7(1), 27-37.

Gosden, H. (2003). Why not give us the full story? Functions of referees' comments in peer reviews of scientific research papers. Journal of English for Academic Purposes, 2, 87-101.

Grabowski, Ł. (2015). Keywords and lexical bundles within English pharmaceutical discourse: A corpus-driven description. English for Specific Purposes, 38, 23 33.

Habibie, P., \& Hyland, K. (2019). Novice Writers and Scholarly Publication: Authors, mentors, gatekeepers. Cham, Switzerland: Palgrave Macmillan.

Halliday, M. A. K., \& Matthiessen, Christian M. I. M. (2014). Halliday's introduction to functional grammar (Fourth Edition). London: Routledge.

Hanauer, D., \& Englander, K. (2011). Quantifying the burden of writing research articles in a second language. Data From Mexican scientists. Written Communication, 28(4), 403-416.

Hewings, M. (2004). An 'important contribution' or 'tiresome reading'? A study of evaluation in peer reviews of journal article submissions. Journal of Applied Linguistics, 1(3), 247-274.

Hyland, K. (2005a). Metadiscourse: Exploring interaction in writing. London: Continuum.

Hyland, K. (2005b). Stance and engagement: a model of interaction in academic discourse. Discourse studies, 7(2), 173-192.

Hyland, K. (2015). Academic publishing: Issues and challenges in the construction of knowledge. Oxford applied linguistics. Oxford: Oxford University Press.

Hyland, K., \& Giuliana, D. (Eds.). (2009). Academic Evaluation: Review genres in university settings. Basingstoke: Palgrave Macmillan. 
Hyland, K., \& Hyland, F. (Eds.). (2019). Feedback in Second Language Writing: Contexts and issues. Cambridge: Cambridge University Press.

Hyland, K. \& Jiang, F. K. (2016). Change of Attitude? A Diachronic Study of Stance. Written communication, 33(3), 251-274.

Hwang, K. (2005) The inferior science and the dominant use of English in knowledge production. A case study of Korean science and technology. Science Communication, 26(4), 390-427.

Jefferson, T., Rudin, M., Brodney Folse, S. and Davidoff, F. (2007) Editorial peer review for improving the quality of reports of biomedical studies. Cochrane Database of Systemic Reviews. Issue 2.

Jiang, F. K., \& Wang, F. (2018). 'This is because ... ': Authorial practice of (un)attending this in academic prose across disciplines. Australian Journal of Linguistics, 38(2), 162-182.

Kourilova, M. (1996). Interactive function of language in peer reviews of medical papers written by NN users of English. UNESCO-ALSED LSP Newsletter, 19 (1): 4-21.

Kwan, B. (2013). Facilitating novice researchers in project publishing during the doctoral years and beyond. Studies in Higher Education, 38, 207-225.

Leech, G. N., Rayson, P., \& Wilson, A. (2001). Word frequencies in written and spoken English: Based on the British National Corpus . Harlow: Longman.

Mertkan, S. (2016). From a doctoral dissertation to journal articles. In C. Sugrue \& S. Mertkan (Eds.), Publishing in the academic world: Passion, purpose and possible futures (pp. 136-149). Abingdon, UK: Routledge.

Merton, R. (1973). The normative structure of science. In R. Merton (ed.) The sociology of science: theoretical and empirical investigations. Chicago: University of Chicago Press.

Mulligan, A., Hall, L., \& Raphael, E. (2013). Peer review in a changing world: An international study measuring the attitudes of researchers. Journal of the American Society for Information Science and Technology, 64, 132-161.

Mungra, P. \&Webber, P. (2010). Peer review process in medical research publications: language and content comments. English for Specific Purposes. 29, 43-53.

Mur Dueñas, P. (2012). Getting research published internationally in English: An ethnographic account of a team of Finance Spanish scholars' struggles. Ibérica 24: $139-156$ 
Nature (2018). Editorial criteria and processes. https://www.nature.com/nature/forauthors/editorial-criteria-and-processes

Noble WS (2017) Ten simple rules for writing a response to reviewers. PLoS Computer Biology 13 (10): e1005730. https://doi.org/10.1371/journal.pcbi.1005730

Oermann, M. H., \& Hays, J. C. (2011). Writing for publication in nursing. (2nd ed.). New York: Springer

O'keeffe, A., Clancy, B., \& Adolphs, S. (2011). Introducing pragmatics in use $\left(1^{\text {st }}\right.$ ed.). London, New York: Routledge.

Paltridge, B. (2015). Referees' comments on submissions to peer-reviewed journals: when is a suggestion not a suggestion? Studies in Higher Education, 40(1), $106-122$.

Paltridge, B. (2017). The discourse of peer review: Reviewing submissions to academic journals. London: Palgrave Macmillan.

Prechelt, L., Graziotin, D. \& Méndez Fernández, D. (2017) A Community’s Perspective on the Status and Future of Peer Review in Software Engineering. Information and Software Technology https://arxiv.org/pdf/1706.07196.pdf

Publishing Research Consortium (2016) Peer review survey 2015. Mark Ware Consulting

Reller, T. (2016). Elsevier publishing - a look at the numbers, and more. Elsevier Connect. https://www.elsevier.com/connect/elsevier-publishing-a-look-at-the-numbers-and$\underline{\text { more }}$

Rigby,J., D. Cox, K. Julian (2018) Journal peer review: a bar or bridge? An analysis of a paper's revision history and turnaround time, and the effect on citation. Scientometrics. Volume 114, $\underline{3}$, pp 1087-1105

Ross, J.S., Gross, C.P., Desai, M.M., Hong, Y., Grant, A.O., Daniels, S.R. (2006). Effect of blinded peer review on abstract acceptance. JAMA, 295, 1675-1680.

Scott, M., \& Tribble, C. (2006). Textual patterns: Key words and corpus analysis in language education. Amsterdam: Benjamins.

Sciullo, N. \& Duncan, M. (2019). Professionalizing Peer Review Suggestions for a More Ethical and Pedagogical Review Process. Journal of Scholarly Publishing . 50 (4).

Shirey, M. (2013). Building scholarly writing capacity in the doctor of nursing practice program. Journal of Professional Nursing, 29 (3): 137-147.

Smith R. (2006). Peer review: a flawed process at the heart of science and journals. Journal of the Royal Society of Medicine, 99(4), 178-182. 
Swales, J. (1996). Occluded genres in the academy. In E. Ventola \& A. Mauranen

(Eds.), Academic Writing: Intercultural and textual issues (pp. 45-58).

Amsterdam: John Benjamins.

Tardy, C. (2019). We are all reviewer 2: a window into the secret world of peer review.

In Habibe, P. \& Hyland, K. (eds). Novice writers and scholarly publication.

London: Palgrave. pp 271-290

Taylor \& Francis (2015). Peer review in 2015: A global view. A white paper. London:

Taylor \& Francis

Ulrich's Periodicals Directory ${ }^{\mathrm{TM}}$ (57th edition) 2019. Proquest.

Wallwork, A. (2016). English for Writing Research Papers. Cham: Springer International Publishing.

Wilcox, C. (2019). Rude paper reviews are pervasive and sometimes harmful. Science, 366 (6472): 1433. 